\title{
Microsurgical training model for residents to approach the orbit and the optic nerve in fresh cadaveric sheep cranium
}

Microsurgical skills and experience have become increasingly important in different surgical procedures. A deep understanding of anatomy remains essential in all surgical fields. Despite this gaining experience in the field of surgical anatomy and particularly microsurgery appears challenging. This is due in part to a lack of high quality relevant simulation, the relative infrequency of microsurgical operations and the increasing complexity of different patients and their diseases.

There are several models described in the literature designed to simulate microsurgical experience, few are valid because they lack anatomical detail and approaches in a realistic set-up..$^{[1]}$ More realistic models using animals can be associated with ethical problems which vary widely internationally. ${ }^{[2]}$ The fact remains that despite different training models being well described in the literature and apparently available for training purposes in the field of microsurgery, the training situation for residents can hardly described as satisfactory. This educational conflict increases stress experienced by hospital residents and can lower morale in relation to continued microsurgical practice. Therefore, the advantages of this model if available in all microsurgical departments offers several training possibilities. ${ }^{[3]}$

Microsurgical training is a difficult process which demands a lot of time, patience, high levels of psychomotor skills and continuous practice. ${ }^{[4-6]}$ Although demanding, this is just one component in the complex system that constitutes surgical treatment. The arduous workload during the residency period means there is limited time to learn a basic set of microsurgery skills, anatomy, ethical and financial limitations. ${ }^{[1,5]}$

\begin{tabular}{|l|l|}
\hline \multicolumn{2}{|c|}{ Access this article online } \\
\hline Quick Response Code: & Website: \\
\hline & www.ruralneuropractice.com \\
\hline & \\
\hline
\end{tabular}

The model described by Altunrende and colleagues in this issue of "Journal of Neurosciences in Rural Practice" for residents in their second to fifth year of their training program contains microsurgical and anatomical aspects of training. ${ }^{[3]}$ More complex components, such as preparation of tissues, shrinking, suction and clipping techniques can be taught and practiced in an appropriate and realistic manner. ${ }^{[2,3,7]}$ There is still a need for realistic models for surgical, and especially microsurgical training, purposes. Complex operations in Neurosciences demand excellent surgical skills in microsurgery to optimise successful treatments for patients in this field. Microsurgery is an essential factor in many forms of modern surgery and should be offered to every trainee. The model described in this issue provides simple, but realistic training conditions.

The model described by Altunrende and colleagues can be further improved by perfusion of the tissues for a more realistic simulation of circulation, even in cadavers ${ }^{[8]}$ Although this was not done here, this might be also an option for advanced training of residents after completion of the basic training using this model. ${ }^{[8]}$

To do this several additional items of equipment are required in the set-up, but this is not prohibitively expensive. The described model is therefore an interesting and useful addition to the training program of residents eager to learn with the possibility of realistic training in the field of microsurgery.

Thomas Mücke

Department of Oral and Maxillofacial Surgery, Technische Universität München, Klinikum Rechts Der Isar, Germany

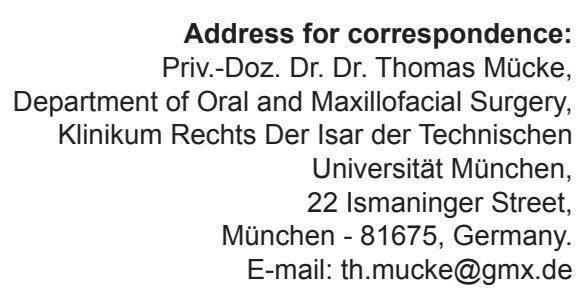

Address for correspondence:

Priv.-Doz. Dr. Dr. Thomas Mücke, partment of Oral and Maxillofacial Surgery, Isar der Technischen Universität München,
22 Ismaninger Street, ünchen - 81675, Germany. E-mail: th.mucke@gmx.de 


\section{References}

1. Mücke T, Borgmann A, Ritschl LM, Kesting MR, Loeffelbein DJ, Wolff KD. Microvascular training of medical students and surgeons-a comparative prospective study. J Craniomaxillofac Surg 2013;41:e187-90.

2. Hamamcioglu MK, Hicdonmez T, Tiryaki M, Cobanoglu S. A laboratory training model in fresh cadaveric sheep brain for microneurosurgical dissection of cranial nerves in posterior fossa. Br J Neurosurg 2008;22:769-71.

3. Altunrende M, Hamamcioglu M, Hicdonmez T, Akcakaya M, Birgilı B, Cobanoglu S. Microsurgical training model for residents to approach to the orbit and the optic nerve in fresh cadaveric sheep cranium. J Neurosci Rural Pract 2014;5:151-4.

4. Acland RD, Sabapathy SR. Practice Manual for Microvascular Surgery. $3^{\text {rd }}$ ed. The Indian Society for Surgery of the Hand (ISSH): 2008. p. 1-120.

5. Lascar I, Totir D, Cinca A, Cortan S, Stefanescu A, Bratianu R, et al.
Training program and learning curve in experimental microsurgery during the residency in plastic surgery. Microsurgery 2007;27:263-7.

6. Scholz M, Mücke T, Hölzle F, Schmieder K, Engelhardt M, Pechlivanis I, et al. A program of microsurgical training for young medical students: Are younger students better? Microsurgery 2006;26:450-5.

7. Mücke T, Scholz M, Kesting MR, Wolff KD, Schmieder K, Harders AG. Microsurgically induced aneurysm models in rats, Part II: Clipping, shrinking and micro-Doppler sonography. Minim Invasive Neurosurg 2008;51:6-10.

8. Aboud E, Al-Mefty O, Yaşargil MG. New laboratory model for neurosurgical training that simulates live surgery. J Neurosurg 2002;97:1367-72.

How to cite this article: Mucke T. Microsurgical training model for residents to approach the orbit and the optic nerve in fresh cadaveric sheep cranium. J Neurosci Rural Pract 2014;5:210-1.

Source of Support: Nil. Conflict of Interest: None declared.

\section{"Quick Response Code" link for full text articles}

The journal issue has a unique new feature for reaching to the journal's website without typing a single letter. Each article on its first page has a "Quick Response Code". Using any mobile or other hand-held device with camera and GPRS/other internet source, one can reach to the full text of that particular article on the journal's website. Start a QR-code reading software (see list of free applications from http://tinyurl.com/ yzlh2tc) and point the camera to the QR-code printed in the journal. It will automatically take you to the HTML full text of that article. One can also use a desktop or laptop with web camera for similar functionality. See http://tinyurl.com/2bw7fn3 or http://tinyurl.com/3ysr3me for the free applications. 